\title{
Novel epididymal proteins as targets for the development of post-testicular male contraception
}

\author{
P Sipilä ${ }^{1,2}$, J Jalkanen ${ }^{1}$, I T Huhtaniemi ${ }^{3}$ and M Poutanen ${ }^{1,2}$ \\ ${ }^{1}$ Department of Physiology, Institute of Biomedicine, University of Turku, Kiinamyllynkatu 10, FIN-20520 Turku, \\ Finland, ${ }^{2}$ Turku Center for Disease Modeling, TCDM, University of Turku, FIN-20520 Turku, Finland and ${ }^{3}$ Department \\ of Reproductive Biology, Imperial College London, Hammersmith Campus, Du Cane Road, London W12 ONN, UK
}

Correspondence should be addressed to M Poutanen; Email: matti.poutanen@utu.fi

\begin{abstract}
Apart from condoms and vasectomy, modern contraceptive methods for men are still not available. Besides hormonal approaches to stop testicular sperm production, the post-meiotic blockage of epididymal sperm maturation carries lots of promise. Microarray and proteomics techniques and libraries of expressed sequence tags, in combination with digital differential display tools and publicly available gene expression databases, are being currently used to identify and characterize novel epididymal proteins as putative targets for male contraception. The data reported indicate that these technologies provide complementary information for the identification of novel highly expressed genes in the epididymis. Deleting the gene of interest by targeted ablation technology in mice or using immunization against the cognate protein are the two preferred methods to functionally validate the function of novel genes in vivo. In this review, we summarize the current knowledge of several epididymal proteins shown either in vivo or in vitro to be involved in the epididymal sperm maturation. These proteins include CRISP1, SPAG11e, DEFB126, carbonyl reductase P34H, CD52, and GPR64. In addition, we introduce novel proteinases and protease inhibitor gene families with potentially important roles in regulating the sperm maturation process. Furthermore, potential contraceptive strategies as well as delivery methods will be discussed. Despite the progress made in recent years, further studies are needed to reveal further details in the epididymal sperm maturation process and the factors involved, in order to facilitate the development of new epididymal contraceptives.
\end{abstract}

Reproduction (2009) 137 379-389

\section{Introduction}

The large number of unintended pregnancies worldwide (nearly $50 \%$ of pregnancies in USA are unintended and $22 \%$ of all pregnancies end in abortion, Finer \& Henshaw 2006) indicates the burning need for new contraceptive methods. While there are multiple contraceptive methods for women, condoms are the only reversible method available for men. Vasectomy is another option for men, but it requires surgery and is not intended to be reversible. However, despite these shortcomings, it has been estimated that male methods account for $37 \%$ of all contraceptive usage (Lye et al. 2004), indicating a need for novel male methods, as well as the willingness of men to use them if available. An ideal male contraceptive would allow normal hormone production and spermatogenesis in the testis but would prevent the post-testicular sperm maturation, thus, blocking the ability of spermatozoa to fertilize the oocytes. There is ample clinical and experimental information that sperm are unable to fertilize if the epididymal phase of their maturation does not occur, indicating the feasibility of the epididymis as the target of a male contraceptive. An ideal method should be rapid, fully and quickly reversible, and without side effects. In order to be regulatable by pharmacological means the ideal drug target would be an enzyme, ion channel or receptor, because small molecular weight pharmacological inhibitors are more feasible to be developed for such proteins. Furthermore, the target should be expressed in a limited number of tissues, preferably only in the epididymis. Owing to the final maturation of spermatozoa in the epididymis, this organ provides a promising target for the development of new male contraceptives.

\section{Epididymal sperm maturation}

When the maturing spermatozoa leave the testis, they are non-motile and unable to fertilize the oocyte in vivo, while their full maturation, including potential to display motility, takes place during transit through the epididymis. The maturational changes in spermatozoa are caused by changes in the luminal ion concentration and the proteins secreted into the lumen by the epididymal epithelium. The maturation includes the 
acquisition of progressive and sustained motility, while the pattern of movement changes from circular (rat) or slightly vibrating (human) into rapid straightforward progression. The flagellum of spermatozoa becomes stiffened, and the neck region less flexible, enabling more rigid movement of the spermatozoa (for review, see Yeung \& Cooper 2002). Furthermore, during epididymal transit the cytoplasmic droplet slides from the base of the sperm head to the end of the midpiece of the flagellum. There are contradictory reports on whether or not the cytoplasmic droplet is shed in the epididymis; however, it seems that it is shed later, during ejaculation (Cooper \& Yeung 2003). A failure in migration of the droplet is often related to subfertility (for review, see Gatti et al. 2004).

During epididymal transit, the spermatozoa also undergo a change in size, shape, and internal structure of the acrosome (Olson et al. 2002). In addition, the sperm cell membrane is under constant remodeling, with attachment and shedding of molecules in a sequential manner (for review, see Cuasnicu et al. 2002, Jones 2002). It has been postulated, that the factors involved in sperm-egg fusion are produced in the proximal epididymis, whereas proteins involved in the sperm-zona binding as well as the decapacitation factors are produced more distally (Cooper 1999).

\section{Methods for identifying putative epididymal target genes}

The rapid improvement of the techniques of analyzing global gene expression in the tissues of interest has provided new tools for novel gene identification. Several groups, including ours, have extensively used microarrays to identify genes expressed in the various epididymal segments and under different regulatory factors in the mouse, rat, and human (Ezer \& Robaire 2003, Hsia \& Cornwall 2004, Sipilä et al. 2006, Zhang et al. 2006, Turner et al. 2007). In addition, proteomics has been utilized by many groups to reveal total protein profiles (proteome) or the secretory proteins (secretome) in the epididymides of rat, stallion, boar, and human (Syntin et al. 1996, Fouchecourt et al. 2000, Dacheux et al. 2006, Yuan et al. 2006). It is currently also possible to use imaging mass spectrometry with which one can investigate the protein content of biological tissue sections at the cellular level in direct correlation with the underlying histology. Such an analysis was recently performed on mouse epididymal samples, and on the basis of this study about 50 proteins were suggested to be expressed in a region-specific manner (Chaurand et al. 2003). However, the technology is in its infancy at present, and still in need of validation by other methods.

Gene discovery and analysis in silico has become a powerful tool of modern biotechnology. Libraries of expressed sequence tags (ESTs) have been used successfully to identify genes expressed in the various epididymal segments of the mouse (Penttinen et al. 2003, Jalkanen et al. 2006a) The UniGene database (http://www.ncbi. $\mathrm{nlm}$.nih.gov/unigene) is a collection of sequences of individual clones of the cDNA libraries of various tissues. These sequences are organized into clusters in such a way that each cluster contains ESTs that overlap in their sequence with at least one other EST of the cluster but not with ESTs of other clusters. Thus, each cluster is likely to contain sequence information of a single gene (Pontius et al. 2003). Among various species, the highest number of EST sequences is available for the human and mouse. The number of ESTs of a specific gene in the library is likely to predict the level of its expression. Furthermore, as EST libraries are available from various tissues, developmental, and diseases stages, the EST database also provides valuable information about the putative tissue distribution of gene expression. By using the digital differential display (DDD) tool at the NCBI (http://www.ncbi.nlm.nih.gov/UniGene/ddd.cgi) or on the TIGR database (http://www.jcvi.org/cms/research/software/) one can search genes present exclusively in the EST library of a certain tissue but not among EST libraries of other tissues. For example, DDD has been used recently to identify two novel members of the Cres subgroup of family two cystatins expressed in the mouse testis, epididymis, cerebrum, and pituitary (Xiang et al. 2008). Other useful databases for obtaining gene expression data from tissues of interest include SAGEmap (www.ncbi.nml.nih.gov/ projects/SAGE/), GUDMAP (http://www.gudmap.org/), and GEO database (http://www.ncbi.nlm.nih.gov/geo/). The strategy used to identify and characterize novel epididymal proteins as putative targets for a male contraceptive is shown in Fig. 1.

EST analysis and proteomic methods provide an unbiased and effective way for the identification of novel, unknown, and epididymis-specific genes. By contrast, the current microarray strategies are based on pre-defined probes for known or predicted transcripts. However, the rapid evolvement of the sequencing and array technologies is likely to overcome this major disadvantage of the microarrays in the near future. The problems with traditional two-dimensional proteomics include poor detection of low abundance proteins and problems in definitive identification of proteins. However, when two dimensions are combined with LC-MS/MS identification of proteins, it is possible to achieve high-confidence identifications owing to the sequence dependency of the data. The major advantage of the cDNA microarray and proteomics approaches is the possibility to analyze gene expression at various experimental stages, while the EST libraries provide static information from limited tissues and experimental conditions. Concerning the epididymis, the number of EST sequences in the UniGene RIKEN epididymal library is also low, further limiting the chances of novel gene identification. The benefits and drawbacks of the EST, cDNA microarray, and proteomics approaches are 


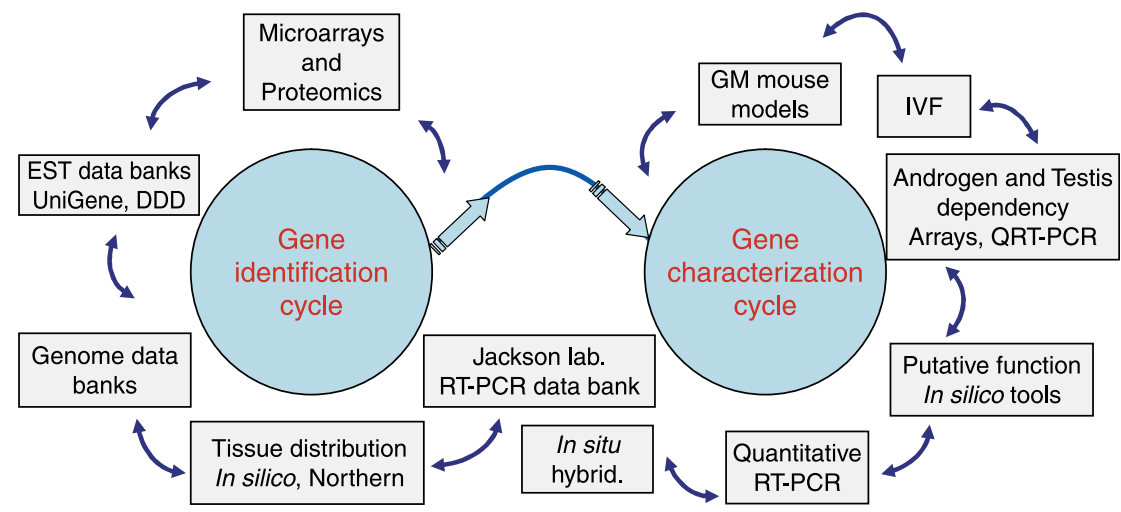

Figure 1 The strategy to identify and characterize novel epididymal proteins as putative targets for a male contraceptive. described in Table 1 . In summary, the various technologies available provide complementary information about novel highly expressed genes in the epididymis.

Although the methods used to identify new epididymal genes and proteins are useful, the caveat in these techniques is that they do not provide evidence for the role of the identified proteins in the sperm maturation process. An opposite strategy applies to the phenotype-based gene discovery process. The $\mathrm{N}$-ethyl$\mathrm{N}$-nitrosourea (ENU)-induced chemical mutagenesis strategy is one of the available methods to generate point mutations in male mouse (and to lesser extend female) germ cells (Kennedy et al. 2005, Handel et al. 2006, Lessard et al. 2007). Mice harboring the mutations are bred to homozygosity and reproductive tests are performed to identify mutations that cause infertility. The final step of the process is the mapping and positional cloning of such a mutation. The Jackson Laboratory provides phenotype description of each mutation generated on their Reprogenomics program (http:// reprogenomics.jax.org), and all the mutant mice are available to the scientific community. The reprogenomics database mainly contains models for male infertility caused by testicular defects. However, the database also includes mutant male mice with

Table 1 Benefits and drawbacks of the expressed sequence tag, microarray and proteomics approaches.

\begin{tabular}{|c|c|c|}
\hline Approach & Benefits & Drawbacks \\
\hline \multirow[t]{2}{*}{ Microarray } & Experimentation possible & $\begin{array}{l}\text { Poor coverage of novel } \\
\text { genes }\end{array}$ \\
\hline & Over 39000 transcripts & $\begin{array}{l}\text { Huge amount of data to } \\
\text { analyze }\end{array}$ \\
\hline \multirow[t]{2}{*}{ Proteomics } & Experimentation possible & $\begin{array}{l}\text { Poor detection of low } \\
\text { abundance proteins }\end{array}$ \\
\hline & $\begin{array}{l}\text { An unbiased way for the } \\
\text { identification of novel } \\
\text { genes }\end{array}$ & $\begin{array}{l}\text { Definite identification of } \\
\text { proteins difficult }\end{array}$ \\
\hline \multirow[t]{2}{*}{ EST library } & $\begin{array}{l}\text { Thirty percent of clusters } \\
\text { represent novel genes }\end{array}$ & $\begin{array}{l}\text { Limited number of genes } \\
\text { in the library }\end{array}$ \\
\hline & $\begin{array}{l}\text { Tissue distribution and } \\
\text { expression level can be } \\
\text { estimated }\end{array}$ & No experimentation \\
\hline
\end{tabular}

post-testicular defects. Upon identification of the mutated genes behind the infertility, new candidates for contraceptive targets are expected to arise.

\section{Functional characterization of novel genes}

The methods used to validate novel genes functionally in vivo have also developed rapidly. Both human and mouse genomes are well characterized, and genomic clones for any gene are available in the form of bacterial artificial chromosomes. This, together with novel cloning techniques available (Angrand et al. 1999, Rivero-Muller et al. 2007) provide us with tools to generate efficiently gene targeting vectors for knockout (KO) mouse production. In addition, the gene-trap libraries (for example www.genetrap.org) with numerous embryonic stem cell clones with a disrupted gene are currently available for the fast generation of mouse models. However, to date, there are only a few genetically modified (GM) mouse models from epididymal genes presenting with defects in sperm maturation and/or function. Nevertheless, such models have revealed the importance of the epididymis for sperm maturation. For example, the Ros 1 proto-oncogene (also known as c-ros, Sonnenberg-Riethmacher et al. 1996) and apolipoprotein E receptor-2 (LRP8, Andersen et al. 2003) KO male mice as well as mice carrying a natural mutation of SHP1 phosphatase gene (Keilhack et al. 2001) lack the most proximal region of the epididymis, initial segment (IS), and are infertile. In addition, transgenic mice expressing the SV 40 virus T-antigen under the Gpx5 promoter in the epididymis (GPX5-Tag2 mice, Sipilä et al. 2002) have dysfunctional IS and male infertility. In all of these GM mouse models, the differentiation of IS is disrupted, resulting in disturbed osmolyte balance of the epididymal fluid, angulation of sperm tails and infertility (Cooper \& Barfield 2006). However, the exact molecular mechanism underlying this defect is still not known.

In addition to the GM mouse models, immunological techniques have been used to study the role of proteins in sperm-zona pellucida (ZP) binding in vivo. In this 
approach, the experimental animals are immunized against a protein specifically present on sperm surface, and the antibodies produced are used to block the sperm motility or ability of sperm to bind to the complementary sites of the oocyte. The epididymal genes with role in fertilization that have been studied using the immunological approach include cysteine-rich secretory protein 1 (Crisp1; Ellerman et al. 2008), carbonyl reductase P34H (Sullivan 2004), CD52 (also known as HE5; Koyama et al. 2007), and serine protease inhibitor-like, with Kunitz and whey acidic protein (WAP) domains 1 (Spin/w1, also known as Eppin; O'Rand et al. 2006).

An intriguing option to study the functions of epididymal genes is to apply in vivo electroporation. In that technique, a DNA construct is injected into the interstitium or lumen of the epididymis using electric pulses that are provided by electric tweezers. After a recovery period, tissue is analyzed. This method has been applied successfully in promoter analysis in vivo (Kirby et al. 2004), and in studying the Ets variant 4 (ETV4, also known as PEA3) transcription factor family and fibroblast growth factor receptor 1 (FGFR1) pathways (Yang et al. 2006). An apparent problem in identifying putative contraceptive drug targets is that many genes have important functions in a variety of different tissues which makes them unattractive drug targets. However, when a signaling pathway necessary for male fertility is identified, this technique in a combination with short hairpin RNA (shRNA) techniques could well provide an efficient strategy to screen epididymal pathway members that would be more suitable drug targets to be further validated in studies in GM animals.

\section{Putative epididymal target genes}

\section{The cysteine-rich secretory protein (Crisp) family}

The family of CRISP proteins consists of four members: Crisp1 (also known as DE), Crisp2 (also known as Tpx1), Crisp3 and Crisp4. Of these family members, mouse Crisp1 and Crisp4 are expressed in the epididymis (Eberspaecher et al. 1995, Jalkanen et al. 2005), Crisp2 in developing spermatocytes (Mizuki et al. 1992) and Crisp3 mainly in the salivary glands, pancreas, and prostate (Haendler et al. 1993). Human homologues have been identified for Crisp2, 3, and 4 (Kratzschmar et al. 1996). Surprisingly, it has been recently reported that CRISP3 is highly expressed in the human cauda epididymidis and ampulla of vas deferens (Udby et al. 2005). Both the mouse and the human CRISP1 proteins are secreted into the epididymal lumen and have been detected on the surface of epididymal spermatozoa. Mouse CRISP1 has been localized in the dorsal region of the acrosome and human CRISP1 in the post-acrosomal region of the sperm head (for review, see Cohen et al. 2007). Two different populations of rat and human
CRISP1 are bound to sperm; a major loosely associated population and a minor tightly bound population. Dissociation of the major population seems to be necessary for the process of capacitation (Roberts et al. 2003). Thus, CRISP1 could be involved in the prevention of precocious capacitation. The minor strongly bound population remaining on sperm surface after capacitation migrates to the equatorial segment during acrosome reaction, and has been suggested to participate in sperm-ZP interaction (Busso et al. 2007) and gamete fusion (for review, see Cohen et al. 2007). Interestingly, immunization against rat CRISP1 protein leads to significant reduction in fertility (Ellerman et al. 2008), postulating that the CRISP family proteins might make putative targets for post-testicular male contraception. However, the recently published CRISP1 KO mouse model was shown to be fully fertile in natural matings and in IVF with cumulus-intact oocytes (Da Ros et al. 2008). Nevertheless, KO sperm exhibited a reduced ability to fertilize ZP-intact oocytes devoid of cumulus cells as well as ZP-free oocytes. As mouse CRISP2 protein was able to bind the mouse oocytes and further inhibit fertilization by CRISP1 KO sperm, it is likely that other Crisp-family members can compensate for the loss of CRISP1 (Da Ros et al. 2008). KO models from CRISP2 and -4 and double/triple $\mathrm{KO}$ mice would provide the ultimate proof for the importance of the CRISP family proteins in fertilization. Nevertheless, since it seems that the protein domain needed for the CRISP-oocyte binding, namely Signature 2 (S2) domain, is evolutionarily conserved within the CRISP family (Cohen et al. 2008), it might be possible to interfere with the functions of all family members at once by targeting that particular domain.

\section{The beta-defensin family}

Beta-defensins belong to a large family (a total of 52 in the mouse) of small antimicrobial peptides. In mammals, beta-defensins are organized into four to five dense clusters on the genome (Patil et al. 2005), and the organization of the clusters is highly similar between the mouse, rat, dog, and human. Furthermore, almost all mouse beta-defensins have been reported to have a human homologue. Recent studies have revealed that many of the beta-defensins are mainly expressed in the male reproductive track, particularly in the epididymis and testis (Patil et al. 2005). In addition to antimicrobial and host defense activities, a role in sperm maturation has been suggested for them on the basis of the localization of several defensins on sperm surface (Liu et al. 2001, Rao et al. 2003). However, only the rat SPAG11e and macaque DEFB126 have been reported to be involved in reproductive function. The rat SPAG11e induces progressive sperm motility by increasing the uptake of calcium by spermatozoa (Zhou et al. 2004) and the macaque DEFB126 has been reported to be involved in 
sperm penetration through the cervical mucus (Tollner et al. 2008), and sperm-ZP recognition and binding (Tollner et al. 2004). However, more studies are needed to confirm the role of this gene family in sperm maturation.

\section{Carbonyl reductase}

Human carbonyl reductase $\mathrm{P} 34 \mathrm{H}$ is a member of the short chain dehydrogenase/reductase superfamily, and it is expressed in the epididymis with the highest level in the corpus region. During the epididymal transit $\mathrm{P} 34 \mathrm{H}$ progressively accumulates in the sperm acrosomal region (reviewed by Sullivan 2004). It has been suggested that $\mathrm{P} 34 \mathrm{H}$ is involved in sperm-ZP binding. This is supported by the results indicating that immunization against $\mathrm{P} 34 \mathrm{H}$ inhibits sperm-zona binding in vitro (Boué et al. 1994). Furthermore, the loss of $\mathrm{P} 34 \mathrm{H}$ from sperm surface has been associated with idiopathic infertility in men (Boué \& Sullivan 1996, Moskovtsev et al. 2007), and human spermatozoa lacking P34H have been shown to be unable to bind to the extracellular matrix of oocyte (Boué \& Sullivan 1996). However, the usefulness of $\mathrm{P} 34 \mathrm{H}$ as a contraceptive target should be critically considered owing to the wide tissue distribution (Felsted \& Bachur 1980) of its expression and the general metabolic role of carbonyl reductases in converting various carbonyl compounds to corresponding alcohols (Wermuth 1981).

\section{CD52 (also known as HE5)}

Human CD52 is a small, highly glycosylated, glycosylphosphatidyl inositol (GPI) -anchored cell membrane glycopeptide expressed in the lymphocytes, distal epididymidis, and vas deferens. Detailed structural analysis of the CD52 protein in the lymphocytes and genital tract revealed that these two populations are distinct in the attached $\mathrm{N}$-linked glycans and GPI-anchor domains (reviewed in Kirchhoff 2002). CD52 is incorporated into the sperm membrane with a GPI-anchor, but the function of this protein in sperm surface remains unknown. Antibodies directed against CD52 yielded in sperm immobilization and inhibition of zona binding when applied in IVF conditions (Mahony et al. 1991, Koyama etal. 2007), and further, antibodies against CD52 occur naturally in some women (Koyama et al. 2007), which leads to difficulties in conceiving. Disappointingly, it was recently shown that CD52 KO male mice are fully fertile both in vivo and in vitro (Yamaguchi et al. 2008). Whether this reflects a species difference between mouse and human remains to be solved.

\section{Gpr64 (also known as HE6)}

Gpr64 is an efferent duct and IS specific member of the LNB-7TM subfamily of G-protein coupled receptors
(Osterhoff et al. 1997). Disruption of the gene in mice results in dysregulation of fluid reabsorption within the efferent ductules, leading to fluid accumulation in the testis, subsequent stasis of spermatozoa within the efferent ducts, and finally to infertility (Davies et al. 2004). Currently, Gpr64 is one of the most promising targets for a post-testicular male contraceptive. It remains to be assured that long-term inhibition of Gpr64 action does not lead to complete atrophy of the germinal epithelium due to fluid accumulation and back pressure in the testis. However, the studies so far carried out with the Gpr64 KO mouse model do not indicate such effects (Davies et al. 2004).

\section{Proteases}

The modification of sperm surface proteins is important for epididymal sperm maturation. These modifications lead to complete removal of proteins or redistribution of modified proteins in the sperm membranes. Examples of such proteolytically processed proteins include the germinal form of angiotensin I converting enzyme ( $g A C E)$ and the disintegrin and metallopeptidase domain 2 (Adam2). gACE is released from the surface of spermatozoa during their transit through caput epididymidis, whereas Adam2 is degraded by two successive cleavages during the caput transit, leaving the protein to the post-acrosomal domain of spermatozoa (Gatti et al. 2004). Other sperm membrane proteins known to be modified during epididymal transit include sperm adhesion molecule 1 (Spam1, also known as $\mathrm{PH}-20$ hyaluronidase), basigin ( $\mathrm{Bsg}$, also known as CE9, CD147, EMMPRIN, gp42, HT-7, neurothelin), and mannosidase 2 alpha B2 (Man2b2, also known as $\alpha$-Dmannosidase; Gatti et al. 2004). However, to date none of the protease(s) responsible for these modifications is known.

\section{The ADAM family}

One of the most studied proteinase families in the epididymis is the disintegrin and metalloprotease (ADAM) gene family, which currently contains about 40 members (http://people.virginia.edu/ jw7g/Table_ of_the_ADAMs.html). The ADAM proteins are considered to have two distinct functions, while some of them act as cell adhesion molecules, and some act as proteases (Primakoff \& Myles 2000). At least 16 ADAM family members are expressed in the testis, and the expression of five has been reported in the epididymis. Of the epididymal ADAM proteins, Adam7 is expressed uniformly in the all epididymal regions and it has been shown to bind to sperm surface, and to be redistributed in the sperm head during acrosome reaction (Oh et al. 2005). Furthermore, on the basis of Adam KO mouse models, it has been suggested that ADAM1a and 
ADAM2 form a protein complex, which in turn is involved in maintaining the stability of other sperm surface proteins including ADAM3 (Nishimura et al. 2004). Studies on the Adam 2 and Adam 3 KO spermatozoa led to the hypothesis that ADAM7 also associates with the ADAM1a/2-ADAM3 heterodimers on the sperm membrane. On the basis of these results, a putative role for ADAM7 in sperm - oocyte binding was suggested (Kim et al. 2006b). Furthermore, ADAM7 does not seem to contain the enzymatically active metalloprotease domain (Lin et al. 2001), and thus it probably acts only as a cell adhesion molecule.

The other epididymal ADAM family member, Adam28, is expressed in the IS and is regulated by testicular factors other than testosterone (Sipilä et al. 2006). There are two splice variants of Adam28 in the epididymis, a membrane bound and a secreted form. Unlike ADAM7, ADAM28 possesses an active metalloprotease domain, and is therefore, suggested to perform proteolytic functions within the epididymis (Jury et al. 1999). In conclusion, the putative role of these epididymal ADAM proteins in sperm maturation process and fertility is yet to be resolved.

$\mathrm{KO}$ mice are available for Adam1a (Nishimura et al. 2004) and $-1 b$ (also known as fertilin $\alpha$, Kim et al. 2006a), Adam2 (also known as fertilin $\beta$, Cho et al. 1998) and Adam3 (also known as cyritestin, Shamsadin et al. 1999, Nishimura et al. 2001). Interestingly, males of all these mouse models are infertile owing to either defects in the ability of sperm to migrate from the uterus into the oviduct (Adam1 and -2), and/or to defects in ZP binding (Adam2 and -3). These findings provide strong evidence for the importance of the ADAM family proteins for fertility.

\section{Protease inhibitors}

It has been reported that the loss of certain ADAM proteins from the sperm surface results in the concomitant disappearance of the other ADAMs (Nishimura et al. 2004, 2007). This suggests that the sperm surface architecture depends on correct localization of its components, and highlights the importance of the sequence of the proteolytic processing of the sperm surface in the epididymal duct. Proteolysis in the epididymal lumen thus needs to be well controlled, and several protease inhibitors expressed in the certain epididymal regions are expected to be responsible for this control. There are several protease inhibitor families present in the epididymis including cystatin (Cornwall \& Hsia 2003), Kunitz (Richardson et al. 2001, Penttinen et al. 2003), Kazal (Moritz et al. 1991, Jalkanen et al. 2006b) and (WAP, (Jalkanen et al. 2006b), and serpin families (Laurell et al. 1992, Hu et al. 2002).

From the cystatin family of cysteine protease inhibitors, Cst8 (also known as Cres) and Cst12 (also known as Cres3) are expressed mainly in the epididymis
(Cornwall \& Hsia 2003), whereas Cst11 (also known as Cres2) has been reported to be epididymis-specific (Cornwall \& Hsia 2003). Classical cystatins are potent cysteine protease inhibitors. However, studies in vitro have shown that Cst8 inhibits the serine protease (prohormone convertase 2) instead of cysteine proteases (Cornwall \& Hsia 2003).

Kazal protease inhibitors also belong to the group of serine protease inhibitors, and they inhibit trypsin-, chymotrypsin-, and elastase-like proteases, including acrosin (for review, see Rawlings et al. 2004). Five members of the Kazal family have been detected in the epididymis, namely Spink2 (serine protease inhibitor, Kazal type 2; Moritz et al. 1991), Spink8, Spink10, Spink11, and Spink12 (Jalkanen et al. 2006b). Analyses of the testicular gene expression of azoospermic infertile men revealed that they were characterized by a 4.2 -fold decrease in Spink2 (previously known as human acrosintrypsin inhibitor HUSI-II) expression compared with fertile men (Rockett et al. 2004). Nevertheless, further studies are required to investigate the significance of this finding, as well as the functions of SPINKs in the epididymis.

The Kunitz protease inhibitors are a large protein family whose members are able to inhibit serine proteases (Pritchard \& Dufton 1999). To our knowledge, Spint4 (Penttinen et al. 2003) is the only pure Kunitz protease inhibitor so far identified in the epididymis. In addition, there are some protease inhibitors with Kunitz and WAP domains present in the epididymis, those including serine protease inhibitor-like, with Kunitz and WAP domains 1 (Spin/w1, also known as Eppin) and (WAP)-type four sulfide core (WFDC) genes -8 and 10 (Jalkanen et al. 2006b, O'Rand et al. 2006). A role in male fertility has been suggested for Spin/w1, since active immunization against Spin/w1 resulted in reversible contraception in five out of nine male monkeys (O'Rand et al. 2004). Because Spinlw1 belongs to the large group of genes expressed both in the testis and epididymis, the role of the epididymal expression in the maintenance of fertility remains unclear. However, the data on Spin/w1 emphasize the role of protease inhibitors in male fertility.

The presence of several proteinase inhibitors from different families is consistent with the hypothesis that correctly timed epididymal proprotein processing is essential for proper sperm maturation. Furthermore, the fact that many of these enzymes have a human homologue, and are highly epididymis-specific (Table 2), indicates that they are putative targets for post-testicular male contraception.

\section{Genes expressed in the testis and epididymis}

$\mathrm{KO}$ mouse models are available for several genes expressed both in the testis and epididymis, and interestingly, many of these models are characterized by defects in male fertility. Such genes include sperm 
Table 2 Epididymal proteinase inhibitors.

\begin{tabular}{|c|c|c|c|c|}
\hline Gene & Gene family & Expressed in & Human homolog & References \\
\hline Spint4 (serine protease inhibitor, Kunitz type 4) & Kunitz & Epididymis & SPINT4 & Penttinen et al. (2003) \\
\hline Spink2 (serine protease inhibitor, Kazal type 2 ) & Kazal & Epididymis, testis, sem. ves. & SPINK2 & Moritz et al. (1991) \\
\hline Spink8 (serine protease inhibitor, Kazal type 8 ) & Kazal & Epididymis, vas deferens & SPINK8 & Jalkanen et al. (2006b) \\
\hline Spink10 (serine protease inhibitor, Kazal type 10 ) & Kazal & Epididymis, brain & nf & Jalkanen et al. (2006b) \\
\hline Spink11 (serine protease inhibitor, Kazal type 11) & Kazal & Epididymis, seminal vesicle & $\mathrm{nf}$ & Jalkanen et al. (2006b) \\
\hline Spink12 (serine protease inhibitor, Kazal type 12) & Kazal & Epididymis & nf & Jalkanen et al. (2006b) \\
\hline $\begin{array}{l}\text { Spin/w1 (serine protease inhibitor-like with Kuniz } \\
\text { and WAP domains 1) }\end{array}$ & $\begin{array}{l}\text { WAP \& } \\
\text { Kunitz }\end{array}$ & Epididymis, testis & WFDC7 & O'Rand et al. (2006) \\
\hline Wfdc2 (WAP-type four disulfide core 2) & WAP & Several tissues & WFDC2 (HE4) & Galgano et al. (2006) \\
\hline Wfdc8 (WAP-type four disulfide core 8 ) & $\begin{array}{l}\text { WAP \& } \\
\quad \text { Kunitz }\end{array}$ & Epididymis, testis & WFDC8 & O'Rand et al. (2006) \\
\hline Wfdc10 (WAP-type four disulfide core 10) & WAP & Epididymis & WFDC10 & Jalkanen et al. (2006b) \\
\hline Wfdc15 (WAP-type four disulfide core 15) & WAP & Epididymis, kidney & $\mathrm{nf}$ & Hagiwara et al. (2003) \\
\hline Cst8 (cystatin 8) & Cystatin & Epididymis, testis, pituitary & CST8 & Cornwall \& Hsia (2003) \\
\hline Cst12 (cystatin 12) & Cystatin & Epididymis, testis & nf & Cornwall \& Hsia (2003) \\
\hline Cst11 (cystatin 11) & Cystatin & Epididymis & CST11 & Cornwall \& Hsia (2003) \\
\hline
\end{tabular}

nf, not found; sem. ves., seminal vesicle.

adhesion molecule 1 (Spam1, also known as $\mathrm{PH}-20)$ and milk fat globule-EGF factor 8 (Mfge8, also known as SED1 and lactadherin). For example, SPAM1 has been shown to have a role in cumulus cell dispersion along with two other testicular hyaluronidases (HYAL1 and HYALP1, Lin et al. 1994, Martin-DeLeon 2006), whereas the MFGE8 KO males were found to be subfertile, owing to a defect in sperm-ZP binding (Ensslin \& Shur 2003). Since these proteins are present on the sperm surface already in the testis, the role of epididymal dysfunction as a cause of the phenotype is not clear. Thus, to distinguish the protein function in the testis and epididymis, the conditional Cre-loxP technique should be applied. However, it is worth noticing that many such proteins are likely to be potential contraceptive drug targets.

\section{From epididymal genes to contraceptives}

For the time being, inhibition of sperm maturation or sperm-oocyte binding by blocking epididymal proteins has only been achieved using immunological approach (Sullivan 2004, O'Rand et al. 2006, Koyama et al. 2007, Ellerman et al. 2008). Reports from immunological studies have raised several concerns such as the possibility of provoking autoimmunity, and the variability in both the degree and duration of response among individuals and reversibility. Contraceptives available for women nowadays are well defined and highly efficient, thus setting the criteria for novel male contraceptives high. Therefore, the above-mentioned concerns for the use of immunological approach have reduced the attractiveness of the approach. A more attractive choice would be the use of small molecule pharmacological inhibitors to target epididymal proteins necessary for the sperm maturation process. Traditionally, small molecule inhibitors of enzymes (for example tyrosine kinases) and receptors (particularly, G-protein coupled receptors) have been used successfully as pharmaceuticals, and more recently progress has been made in the development of inhibitors of protein-protein interaction as well (Gadek \& Nicholas 2003). Small molecule inhibitors are often end products of rational design, on the basis of well characterized targets. Interestingly, cell-based drug screening strategies, which have applied the available small molecule libraries, have identified several potential drugs, for example for cancer therapy, over the last few years (Gudkov 2004, Vita \& Henriksson 2006). Importantly, this means that when a suitable target protein is identified, potential inhibitors can be quickly identified, before the target's interactions with other proteins are fully characterized. Nevertheless, even though a number of novel potential drug targets are emerging, epididymal male contraceptives are still years away from clinical use, since the appropriate lead compounds need first to be identified and developed further in vitro, in preclinical in vivo models, and finally in clinical trials.

The presence of the blood-epididymis barrier (Cyr et al. 2002) presents a major challenge in delivering potential contraceptive drugs to the epididymis. Drug delivery through the blood-brain and blood-testis barriers have been studied in more detail, and solutions from those systems are expected to apply for the epididymis as well. For example, there are already potential contraceptive drugs (for example Miglustat, N-butyldeoxynojirimycin, NB-DNJ, Amory et al. 2007) that appear to traverse through the blood-testis barrier by passive diffusion. Another strategy to cross the bloodepididymis barrier could be the use of endogenous transport systems including glucose, amino acid carriers, and receptor-mediated transcytosis. For example, another putative non-hormonal contraceptive, Adjudin (1-(2,4-dichlorobenzyl)-1 $\mathrm{H}$-indazole-3-carbohydrazide), was found to be unacceptable as a male contraceptive in humans owing to liver inflammation and 
muscle atrophy (Mruk et al. 2006). To circumvent the systemic side effects adjuvin was conjugated to a modified FSH mutant protein, which lacked hormonal activity but retained its receptor-binding ability (Mruk et al.2006). Thus, the use of such shuttle molecules would enable both drug delivery through the blood-epididymis barrier as well as to target drug molecules to specific tissues/cells. However, possible epididymal shuttle molecules are yet to be discovered. Over the past few years, considerable effort has been put to developing nanoparticles loaded with liposomes for delivery of drugs into the brain. For example, doxorubicin bound to polysorbate-coated nanoparticles crosses the bloodbrain barrier and results in better treatment response than doxorubicin alone (Steiniger et al. 2004). However, nanoparticles are given as injections, which is one of the least accepted contraceptive methods among men (Martin et al. 2000), and they have to be coated with suitable surfactant, which makes them expensive. These disadvantages are acceptable for cancer drugs, but not for contraceptives meant for every day use.

In addition to epididymal protein targets, there are several other aspects in epididymal functions that could serve as contraceptive targets. They have been reviewed recently by Cooper (2002) and will not be discussed in this review.

\section{Conclusions}

There is a large body of information on the modifications occurring on sperm surface during their epididymal transit. However, only few of these modifications have been shown to have direct effects on sperm function. Furthermore, in most cases, the molecular events leading to the modifications on sperm surface are not known. However, several epididymal proteins have been shown to be involved in epididymal sperm maturation, and several proteins and protein families expected to be important in regulating the sperm maturation process have been identified, though not fully characterized. Many of these proteins have been described previously in several review articles (Kirchhoff 1999, Cornwall et al. 2002). The advanced high-throughput methods such as expression profiling and in silico analyses together with targeted mutagenesis in mice are expected to speed up the identification and functional validation of the key players in the sperm maturation process. Understanding the molecular mechanisms essential for epididymal sperm maturation will not only provide new targets for post-testicular male contraceptives, but will also further increase our understanding of reasons of idiopathic male infertility.

\section{Declaration of interest}

The authors declare that there is no conflict of interest that would prejudice the impartiality of this scientific work.

\section{Funding}

This work was supported by grants from The Academy of Finland and The Sigrid Jusélius Foundation.

\section{Acknowledgements}

We thank Leena Strauss, PhD, for constructive comments on the manuscript.

\section{References}

Amory JK, Muller CH, Page ST, Leifke E, Pagel ER, Bhandari A, Subramanyam B, Bone W, Radlmaier A \& Bremner WJ 2007 Miglustat has no apparent effect on spermatogenesis in normal men. Human Reproduction 22 702-707.

Andersen $\mathrm{OM}$, Yeung $\mathrm{CH}$, Vorum $\mathrm{H}$, Wellner $\mathrm{M}$, Andreassen $\mathrm{TK}$, Erdmann B, Mueller EC, Herz J, Otto A, Cooper TG et al. 2003 Essential role of the apolipoprotein $\mathrm{E}$ receptor-2 in sperm development. Journal of Biological Chemistry 278 23989-23995.

Angrand PO, Daigle N, van der Hoeven F, Scholer HR \& Stewart AF 1999 Simplified generation of targeting constructs using ET recombination. Nucleic Acids Research 27 e16.

Boué F \& Sullivan R 1996 Cases of human infertility are associated with the absence of $\mathrm{P} 34 \mathrm{H}$, and epididymal sperm antigen. Biology of Reproduction 54 1018-1024.

Boué F, Bérubé B, De Lamirande E, Gagnon C \& Sullivan R 1994 Human sperm-zona pellucida interaction is inhibited by an antibody against a hamster sperm protein. Biology of Reproduction 51 577-587.

Busso D, Cohen DJ, Maldera JA, Dematteis A \& Cuasnicu PS 2007 A novel function for CRISP1 in rodent fertilization: involvement in sperm-zona pellucida interaction. Biology of Reproduction 77 848-854.

Chaurand P, Fouchecourt S, DaGue BB, Xu BJ, Reyzer ML, OrgebinCrist MC \& Caprioli RM 2003 Profiling and imaging proteins in the mouse epididymis by imaging mass spectrometry. Proteomics 3 2221-2239.

Cho C, Bunch DO, Faure JE, Goulding EH, Eddy EM, Primakoff P \& Myles DG 1998 Fertilization defects in sperm from mice lacking fertilin beta. Science 281 1857-1859.

Cohen DJ, Da Ros VG, Busso D, Ellerman DA, Maldera JA, Goldweic N \& Cuasnicu PS 2007 Participation of epididymal cysteine-rich secretory proteins in sperm-egg fusion and their potential use for male fertility regulation. Asian Journal of Andrology 9 528-532.

Cohen DJ, Busso D, Da Ros V, Ellerman DA, Maldera JA, Goldweic N \& Cuasnicu PS 2008 Participation of cysteine-rich secretory proteins (CRISP) in mammalian sperm-egg interaction. International Journal of Developmental Biology 52 737-742.

Cooper TG 1999 Epididymis. In Encyclopedia of Reproduction, pp 1-17. Eds E Knobil \& J Neill. San Diego, CA: Academic Press.

Cooper TG 2002 The epididymis as a target for male contraception. In The Epididymis: From Molecules to Clinical Practice, pp 483-502. Eds B Robaire \& BT Hinton. New York: Kluwer Academic/Plenum Publishers.

Cooper TG \& Barfield JP 2006 Utility of infertile male models for contraception and conservation. Molecular and Cellular Endocrinology $250206-211$.

Cooper TG \& Yeung CH 2003 Acquisition of volume regulatory response of sperm upon maturation in the epididymis and the role of the cytoplasmic droplet. Microscopy Research and Technique 61 28-38.

Cornwall GA \& Hsia N 2003 A new subgroup of the family 2 cystatins. Molecular and Cellular Endocrinology 200 1-8.

Cornwall GA, Lareyre J-, Matusik RJ, Hinton BT \& Orgebin-Crist MC 2002 Gene expression and epididymal function. In The Epididymis: From Molecules to Clinical Practice, pp 169-200. Eds B Robaire \& BT Hinton. New York: Kluwer Academic/Plenum Publishers.

Cuasnicu PS, Cohen DJ, Ellerman DA, Busso D, Da Ros VG \& Morgenfeld MM 2002 Changes in specific sperm proteins during epididymal maturation. In The Epididymis: From Molecules to Clinical Practice, pp 389-403. Eds B Robaire \& BT Hinton. New York: Kluwer Academic/ Plenum Publisher. 
Cyr DG, Finnson K, Dufresne J \& Gregory M 2002 Cellular interactions and the blood-epididymal barrier. In The Epididymis: From Molecules to Clinical Practice, pp 103-118. Eds B Robaire \& BT Hinton. New York: Kluwer Academic/Plenum Publishers.

Dacheux JL, Belghazi M, Lanson Y \& Dacheux F 2006 Human epididymal secretome and proteome. Molecular and Cellular Endocrinology 250 36-42.

Davies B, Baumann C, Kirchhoff C, Ivell R, Nubbemeyer R, Habenicht UF, Theuring F \& Gottwald U 2004 Targeted deletion of the epididymal receptor HE6 results in fluid dysregulation and male infertility. Molecular and Cellular Biology 24 8642-8648.

Eberspaecher U, Roosterman D, Kratzschmar J, Haendler B, Habenicht UF, Becker A, Quensel C, Petri T, Schleuning WD \& Donner P 1995 Mouse androgen-dependent epididymal glycoprotein CRISP-1 (DE/AEG): isolation, biochemical characterization, and expression in recombinant form. Molecular Reproduction and Development 42 157-172.

Ellerman DA, Busso D, Maldera JA \& Cuasnicu PS 2008 Immunocontraceptive properties of recombinant sperm protein DE: implications for the development of novel contraceptives. Fertility and Sterility $\mathbf{8 9}$ 199-205.

Ensslin MA \& Shur BD 2003 Identification of mouse sperm SED1, a bimotif EGF repeat and discoidin-domain protein involved in sperm-egg binding. Cell 114 405-417.

Ezer N \& Robaire B 2003 Gene expression is differentially regulated in the epididymis after orchidectomy. Endocrinology 144 975-988.

Felsted RL \& Bachur NR 1980 Mammalian carbonyl reductases. Drug Metabolism Reviews 11 1-60.

Finer LB \& Henshaw SK 2006 Disparities in rates of unintended pregnancy in the United States, 1994 and 2001. Perspectives on Sexual and Reproductive Health 38 90-96.

Fouchecourt S, Metayer S, Locatelli A, Dacheux F \& Dacheux JL 2000 Stallion epididymal fluid proteome: qualitative and quantitative characterization; secretion and dynamic changes of major proteins. Biology of Reproduction 62 1790-1803.

Gadek TR \& Nicholas JB 2003 Small molecule antagonists of proteins. Biochemical Pharmacology 65 1-8.

Galgano MT, Hampton GM \& Frierson HF Jr 2006 Comprehensive analysis of HE4 expression in normal and malignant human tissues. Modern Pathology 19 847-853.

Gatti JL, Castella S, Dacheux F, Ecroyd H, Metayer S, Thimon V \& Dacheux JL 2004 Post-testicular sperm environment and fertility. Animal Reproduction Science 82-83 321-339.

Gudkov AV 2004 Cancer drug discovery: the wisdom of imprecision. Nature Medicine 10 1298-1299.

Haendler B, Kratzschmar J, Theuring F \& Schleuning WD 1993 Transcripts for cysteine-rich secretory protein-1 (CRISP-1; DE/AEG) and the novel related CRISP-3 are expressed under androgen control in the mouse salivary gland. Endocrinology 133 192-198.

Hagiwara K, Kikuchi T, Endo Y, Huqun, Usui K, Takahashi M, Shibata N, Kusakabe T, Xin H, Hoshi S et al. 2003 Mouse SWAM1 and SWAM2 are antibacterial proteins composed of a single whey acidic protein motif. Journal of Immunology 170 1973-1979.

Handel MA, Lessard C, Reinholdt L, Schimenti J \& Eppig JJ 2006 Mutagenesis as an unbiased approach to identify novel contraceptive targets. Molecular and Cellular Endocrinology 250 201-205.

Hsia N \& Cornwall GA 2004 DNA microarray analysis of region-specific gene expression in the mouse epididymis. Biology of Reproduction $\mathbf{7 0}$ 448-457.

Hu ZH, Liu Q, Shang Q, Zheng M, Yang J \& Zhang YL 2002 Identification and characterization of a new member of serpin family- HongrES1 in rat epididymis. Cell Research 12 407-410.

Jalkanen J, Huhtaniemi I \& Poutanen M 2005 Mouse cysteine-rich secretory protein 4 (CRISP4): a member of the Crisp family exclusively expressed in the epididymis in an androgen-dependent manner. Biology of Reproduction 72 1268-1274.

Jalkanen J, Shariatmadari R, Pujianto DA, Sipilä P, Huhtaniemi I \& Poutanen M 2006a Identification of novel epididymal genes by expression profiling and in silico gene discovery. Molecular and Cellular Endocrinology 250 163-168.

Jalkanen J, Kotimäki M, Huhtaniemi I \& Poutanen M 2006b Novel epididymal protease inhibitors with Kazal or WAP family domain. Biochemical and Biophysical Research Communications 349 245-254.
Jones R 2002 Plasma membrane composition and organization during maturation of spermatozoa in the epididymis. In The Epididymis: From Molecules to Clinical Practice, pp 405-416. Eds B Robaire \& BT Hinton. Kluwer Academic/Plenum Publishers: New York.

Jury JA, Perry AC \& Hall L 1999 Identification, sequence analysis and expression of transcripts encoding a putative metalloproteinase, eMDC II, in human and macaque epididymis. Molecular Human Reproduction 5 1127-1134.

Keilhack H, Muller M, Bohmer SA, Frank C, Weidner KM, Birchmeier W, Ligensa T, Berndt A, Kosmehl H, Gunther B et al. 2001 Negative regulation of Ros receptor tyrosine kinase signaling. An epithelial function of the $\mathrm{SH} 2$ domain protein tyrosine phosphatase SHP-1. Journal of Cell Biology 152 325-334.

Kennedy CL, O'Connor AE, Sanchez-Partida LG, Holland MK, Goodnow CC, de Kretser DM \& O'Bryan MK 2005 A repository of ENU mutant mouse lines and their potential for male fertility research. Molecular Human Reproduction 11 871-880.

Kim E, Yamashita M, Nakanishi T, Park KE, Kimura M, Kashiwabara S \& Baba T 2006a Mouse sperm lacking ADAM1b/ADAM2 fertilin can fuse with the egg plasma membrane and effect fertilization. Journal of Biological Chemistry 281 5634-5639.

Kim T, Oh J, Woo JM, Choi E, Im SH, Yoo YJ, Kim DH, Nishimura H \& Cho C 2006b Expression and relationship of male reproductive ADAMs in mouse. Biology of Reproduction 74 744-750.

Kirby JL, Yang L, Labus JC, Lye RJ, Hsia N, Day R, Cornwall GA \& Hinton BT 2004 Characterization of epididymal epithelial cell-specific gene promoters by in vivo electroporation. Biology of Reproduction 71 613-619.

Kirchhoff C 1999 Gene expression in the epididymis. International Review of Cytology 188 133-202.

Kirchhoff C 2002 Specific gene expression in the human and non-human primate epididymis. In The Epididymis: From Molecules to Clinical Practice, pp 201-218. Eds B Robaire \& BT Hinton. New York: Kluwer Academic/Plenum Publishers.

Koyama K, Ito K \& Hasegawa A 2007 Role of male reproductive tract CD52 (mrt-CD52) in reproduction. Society of Reproduction and Fertility $\mathbf{6 3}$ 103-110.

Kratzschmar J, Haendler B, Eberspaecher U, Roosterman D, Donner P \& Schleuning WD 1996 The human cysteine-rich secretory protein (CRISP) family. Primary structure and tissue distribution of CRISP-1, CRISP-2 and CRISP-3. European Journal of Biochemistry 236 827-836.

Laurell M, Christensson A, Abrahamsson PA, Stenflo J \& Lilja H 1992 Protein $C$ inhibitor in human body fluids. Seminal plasma is rich in inhibitor antigen deriving from cells throughout the male reproductive system. Journal of Clinical Investigation 89 1094-1101.

Lessard C, Lothrop H, Schimenti JC \& Handel MA 2007 Mutagenesisgenerated mouse models of human infertility with abnormal sperm. Human Reproduction 22 159-166.

Lin Y, Mahan K, Lathrop WF, Myles DG \& Primakoff P 1994 A hyaluronidase activity of the sperm plasma membrane protein $\mathrm{PH}-20$ enables sperm to penetrate the cumulus cell layer surrounding the egg. Journal of Cell Biology 125 1157-1163.

Lin YC, Sun GH, Lee YM, Guo YW \& Liu HW 2001 Cloning and characterization of a complementary DNA encoding a human epididymis-associated disintegrin and metalloprotease 7 protein. Biology of Reproduction 65 944-950.

Liu Q, Hamil KG, Sivashanmugam P, Grossman G, Soundararajan R, Rao AJ, Richardson RT, Zhang YL, O'Rand MG, Petrusz P et al. 2001 Primate epididymis-specific proteins: characterization of ESC42, a novel protein containing a trefoil-like motif in monkey and human. Endocrinology 142 4529-4539.

Lye RJ, Sipilä P, Vernet P \& Wagenfeld A 2004 Male contraception - a topic with many facets. Molecular and Cellular Endocrinology 216 75-82.

Mahony MC, Fulgham DL, Blackmore PF \& Alexander NJ 1991 Evaluation of human sperm-zona pellucida tight binding by presence of monoclonal antibodies to sperm antigens. Journal of Reproductive Immunology 19 269-285.

Martin CW, Anderson RA, Cheng L, Ho PC, van der Spuy Z, Smith KB, Glasier AF, Everington D \& Baird DT 2000 Potential impact of hormonal male contraception: cross-cultural implications for development of novel preparations. Human Reproduction 15 637-645. 
Martin-DeLeon PA 2006 Epididymal SPAM1 and its impact on sperm function. Molecular and Cellular Endocrinology 250 114-121.

Mizuki N, Sarapata DE, Garcia-Sanz JA \& Kasahara M 1992 The mouse male germ cell-specific gene Tpx-1: molecular structure, mode of expression in spermatogenesis, and sequence similarity to two nonmammalian genes. Mammalian Genome 3 274-280.

Moritz A, Lilja H \& Fink E 1991 Molecular cloning and sequence analysis of the cDNA encoding the human acrosin-trypsin inhibitor (HUSI-II). FEBS Letters 278 127-130.

Moskovtsev SI, Jarvi K, Légaré C, Sullivan R \& Mullen JBM 2007 Epididymal $\mathrm{P} 34 \mathrm{H}$ protein deficiency in men evaluated for infertility. Fertility and Sterility 88 1455-1457.

Mruk DD, Wong CH, Silvestrini B \& Cheng CY 2006 A male contraceptive targeting germ cell adhesion. Nature Medicine 12 1323-1328.

Nishimura H, Cho C, Branciforte DR, Myles DG \& Primakoff P 2001 Analysis of loss of adhesive function in sperm lacking cyritestin or fertilin beta. Developmental Biology 233 204-213.

Nishimura H, Kim E, Nakanishi T \& Baba T 2004 Possible function of the ADAM1a/ADAM2 Fertilin complex in the appearance of ADAM3 on the sperm surface. Journal of Biological Chemistry 279 34957-34962.

Nishimura H, Myles DG \& Primakoff P 2007 Identification of an ADAM2ADAM3 complex on the surface of mouse testicular germ cells and cauda epididymal sperm. Journal of Biological Chemistry 282 17900-17907.

Oh J, Woo JM, Choi E, Kim T, Cho BN, Park ZY, Kim YC, Kim DH \& Cho C 2005 Molecular, biochemical, and cellular characterization of epididymal ADAMs, ADAM7 and ADAM28. Biochemical and Biophysical Research Communications 331 1374-1383.

Olson GE, NagDas SK \& Winfrey VP 2002 Structural differentiation of spermatozoa during post-testicular maturation. In The Epididymis: From Molecules to Clinical Practice, pp 371-387. Eds B Robaire \& BT Hinton. New York: Kluwer Academic/Plenum Publishers.

$\mathrm{O}^{\prime}$ Rand MG, Widgren EE, Sivashanmugam P, Richardson RT, Hall SH, French FS, VandeVoort CA, Ramachandra SG, Ramesh V \& Jagannadha Rao A 2004 Reversible immunocontraception in male monkeys immunized with eppin. Science 306 1189-1190.

O'Rand MG, Widgren EE, Wang Z \& Richardson RT 2006 Eppin: an effective target for male contraception. Molecular and Cellular Endocrinology 250 157-162.

Osterhoff C, Ivell R \& Kirchhoff C 1997 Cloning of a human epididymisspecific mRNA, HE6, encoding a novel member of the seven transmembrane-domain receptor superfamily. DNA and Cell Biology 16 379-389.

Patil AA, Cai Y, Sang Y, Blecha F \& Zhang G 2005 Cross-species analysis of the mammalian beta-defensin gene family: presence of syntenic gene clusters and preferential expression in the male reproductive tract. Physiological Genomics 23 5-17.

Penttinen J, Pujianto DA, Sipilä P, Huhtaniemi I \& Poutanen M 2003 Discovery in silico and characterization in vitro of novel genes exclusively expressed in the mouse epididymis. Molecular Endocrinology 17 2138-2151.

Pontius JU, Wagner L \& Schuler GD 2003 UniGene: a unified view of the transcriptome. In The NCBI Handbook. www.ncbi.nlm.nih.gov/.

Primakoff P \& Myles DG 2000 The ADAM gene family: surface proteins with adhesion and protease activity. Trends in Genetics $\mathbf{1 6}$ 83-87.

Pritchard L \& Dufton MJ 1999 Evolutionary trace analysis of the Kunitz/BPTI family of proteins: functional divergence may have been based on conformational adjustment. Journal of Molecular Biology 285 1589-1607.

Rao J, Herr JC, Reddi PP, Wolkowicz MJ, Bush LA, Sherman NE, Black M \& Flickinger CJ 2003 Cloning and characterization of a novel spermassociated isoantigen (E-3) with defensin- and lectin-like motifs expressed in rat epididymis. Biology of Reproduction 68 290-301.

Rawlings ND, Tolle DP \& Barrett AJ 2004 Evolutionary families of peptidase inhibitors. Biochemical Journal 378 705-716.

Richardson RT, Sivashanmugam P, Hall SH, Hamil KG, Moore PA, Ruben SM, French FS \& O'Rand M 2001 Cloning and sequencing of human Eppin: a novel family of protease inhibitors expressed in the epididymis and testis. Gene 270 93-102.
Rivero-Muller A, Lajic S \& Huhtaniemi I 2007 Assisted large fragment insertion by Red/ET-recombination (ALFIRE)-an alternative and enhanced method for large fragment recombineering. Nucleic Acids Research 35 e78.

Roberts KP, Wamstad JA, Ensrud KM \& Hamilton DW 2003 Inhibition of capacitation-associated tyrosine phosphorylation signaling in rat sperm by epididymal protein Crisp-1. Biology of Reproduction 69 572-581.

Rockett JC, Patrizio P, Schmid JE, Hecht NB \& Dix DJ 2004 Gene expression patterns associated with infertility in humans and rodent models. Mutation Research 549 225-240.

Da Ros VG, Maldera JA, Willis WD, Cohen DJ, Goulding EH, Gelman DM, Rubinstein M, Eddy EM \& Cuasnicu PS 2008 Impaired sperm fertilizing ability in mice lacking Cysteine-RIch Secretory Protein 1 (CRISP1). Developmental Biology 320 12-18.

Shamsadin R, Adham IM, Nayernia K, Heinlein UA, Oberwinkler H \& Engel W 1999 Male mice deficient for germ-cell cyritestin are infertile. Biology of Reproduction 61 1445-1451.

Sipilä P, Cooper TG, Yeung $\mathrm{CH}$, Mustonen $\mathrm{M}$, Penttinen J, Drevet J, Huhtaniemi I \& Poutanen M 2002 Epididymal dysfunction initiated by the expression of simian virus $40 \mathrm{~T}$-antigen leads to angulated sperm flagella and infertility in transgenic mice. Molecular Endocrinology 16 2603-2617.

Sipilä P, Pujianto DA, Shariatmadari R, Nikkilä J, Lehtoranta M, Huhtaniemi IT \& Poutanen M 2006 Differential endocrine regulation of genes enriched in initial segment and distal caput of the mouse epididymis as revealed by genome-wide expression profiling. Biology of Reproduction 75 240-251.

Sonnenberg-Riethmacher E, Walter B, Riethmacher D, Godecke S \& Birchmeier C 1996 The c-ros tyrosine kinase receptor controls regionalization and differentiation of epithelial cells in the epididymis. Genes and Development 10 1184-1193.

Steiniger SC, Kreuter J, Khalansky AS, Skidan IN, Bobruskin AI, Smirnova ZS, Severin SE, Uhl R, Kock M, Geiger KD et al. 2004 Chemotherapy of glioblastoma in rats using doxorubicin-loaded nanoparticles. International Journal of Cancer 109 759-767.

Sullivan R 2004 Male fertility markers, myth or reality. Animal Reproduction Science 82-83 341-347.

Syntin P, Dacheux F, Druart X, Gatti JL, Okamura N \& Dacheux JL 1996 Characterization and identification of proteins secreted in the various regions of the adult boar epididymis. Biology of Reproduction $\mathbf{5 5}$ 956-974.

Tollner TL, Yudin AI, Treece CA, Overstreet JW \& Cherr GN 2004 Macaque sperm release ESP13.2 and PSP94 during capacitation: the absence of ESP13.2 is linked to sperm-zona recognition and binding. Molecular Reproduction and Development 69 325-337.

Tollner TL, Yudin AI, Treece CA, Overstreet JW \& Cherr GN 2008 Macaque sperm coating protein DEFB126 facilitates sperm penetration of cervical mucus. Human Reproduction 23 2523-2534.

Turner TT, Johnston DS, Finger JN \& Jelinsky SA 2007 Differential gene expression among the proximal segments of the rat epididymis is lost after efferent duct ligation. Biology of Reproduction 77 165-171.

Udby L, Bjartell A, Malm J, Egesten A, Lundwall A, Cowland JB, Borregaard N \& Kjeldsen L 2005 Characterization and localization of cysteine-rich secretory protein 3 (CRISP-3) in the human male reproductive tract. Journal of Andrology 26 333-342.

Vita M \& Henriksson M 2006 The Myc oncoprotein as a therapeutic target for human cancer. Seminars in Cancer Biology 16 318-330.

Wermuth B 1981 Purification and properties of an NADPH-dependent carbonyl reductase from human brain. Relationship to prostaglandin 9-ketoreductase and xenobiotic ketone reductase. Journal of Biological Chemistry 256 1206-1213.

Xiang Y, Nie DS, Zhang QJ, Zhu WB, Du J, Li W \& Lu GX 2008 Cloning, characterization and identification of Rcet1-v1 and Rcet1-v2, two novel splice variants of mouse Rcet1 related to Cres subgroup of family 2 cystatins. DNA Sequence 19 13-19.

Yamaguchi R, Yamagata K, Hasuwa H, Inano E, Ikawa M \& Okabe M 2008 Cd52, known as a major maturation-associated sperm membrane antigen secreted from the epididymis, is not required for fertilization in the mouse. Genes to Cells 13 851-861.

Yang L, Fox SA, Kirby JL, Troan BV \& Hinton BT 2006 Putative regulation of expression of members of the Ets variant 4 transcription factor family and their downstream targets in the rat epididymis. Biology of Reproduction 74 714-720. 
Yeung CH \& Cooper TG 2002 Acquisition and development of sperm motility upon maturation in the epididymis. In The Epididymis: From Molecules to Clinical Practice, pp 417-434. Eds B Robaire \& BT Hinton. New York: Kluwer Academic/Plenum Publishers.

Yuan H, Liu A, Zhang L, Zhou H, Wang Y, Zhang H, Wang G, Zeng R, Zhang $\mathbf{Y}$ \& Chen $\mathbf{Z} 2006$ Proteomic profiling of regionalized proteins in rat epididymis indicates consistency between specialized distribution and protein functions. Journal of Proteome Research 5 299-307.

Zhang JS, Liu Q, Li YM, Hall SH, French FS \& Zhang YL 2006 Genome-wide profiling of segmental-regulated transcriptomes in human epididymis using oligo microarray. Molecular and Cellular Endocrinology 250 169-177.
Zhou CX, Zhang YL, Xiao L, Zheng M, Leung KM, Chan MY, Lo PS, Tsang LL, Wong HY, Ho LS et al. 2004 An epididymis-specific betadefensin is important for the initiation of sperm maturation. Nature Cell Biology 6 458-464.

Received 20 March 2008

First decision 14 May 2008

Revised manuscript received 2 December 2008

Accepted 8 January 2009 